\title{
WALL CONDITIONING AND PLASMA SURFACE INTERACTIONS IN DIII-D
}

\author{
by \\ G.L. JACKSON, B.L. DOYLE,* D.N. HILL, † W.L. HSU, $\ddagger$ \\ P.I. PETERSEN, M.S. SCHAFFER, P.L. TAYLOR, \\ T.S. TAYLOR, D.S. WALSH, ${ }^{*}$ and J. WINTER ${ }^{\S}$
}

This is a preprint of a paper to be presented at the Sixteenth Symposium on Fusion Technology, September 3-7, 1990, in London, England and to be printed in the Procsedings.

\author{
Work supported by \\ U.S. Department of Energy \\ Contract DE-AC03-89ER51114
}

* Sandia Narional Laboratory, Albuquerque, NM.

${ }^{\dagger}$ Lawrence Livermore National Laboratory, Livermore, CA.

+ Sandia National Laboratory, Livernore, CA.

$\S$ Institute of Plasmaphysics, KFA, Julick, EPG.

\section{GENERAL ATONIICS PROJECT 3466 SEPTEMBER 1990}

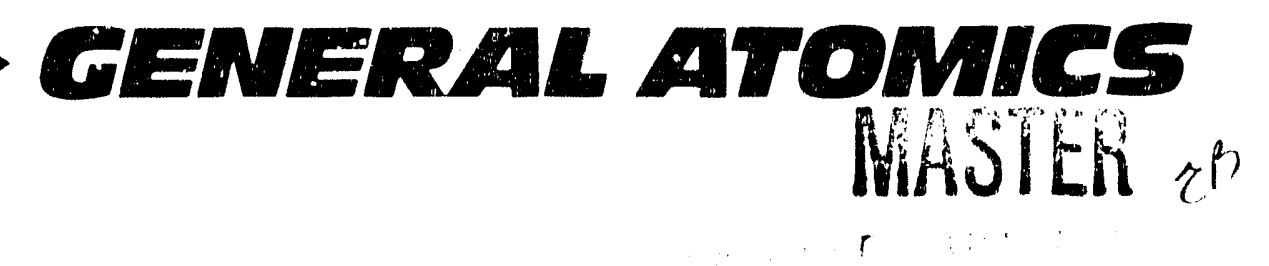




\title{
WALL CONDITIONING AND PLASMA SURFACE INTERACTIONS IN DIII-D
}

\author{
G.L. JACKSON, B.L. DOYLE, D.N. HILL, 'W.L. HSU, P.I. PETERSEN, M.S. SCHAFFER, P.L. TAYLOR, T.S. TAYLOR, \\ D.S. WALSH, * and J. WINTER
}

General Atomics, P.O. Box 85608, San Diego, California 92186-9784, USA ...

- Sandia National Labcratory, Albuquerque, USA.

'Lawrence Livermore National Laboratory, USA.

'Sandia National Laboratory, Livermore, USA.

Institute of Plasmaphysics, KFA, Julich, FRG.

Wall conditioning is used in DIII-D for both reduction of impurity infuxes and particle control. The methods used include: baking, puised discharge cleaning, bydrogen glow cleaning, helium and neon glow conditioning, and carbonization. Helium glow wall conditioning applied beiore every tokamak discharge has been effective in impurity removal and particle control and has siznificantly expanded the parameter space in which DIII-D operates to include limitex and obmic $\mathrm{B}$-mode discharges and higher $\beta_{\mathrm{T}}$ at low $q$. The highest values of divertor plasma current (3.0 MA) and stored energy (3.6 MJ) and peaked density profiles in H-mode discharges bave bet:n observed after carbonization. Divertor physics studies in DIII-D include sweeping the X-point to reduce peak heat loads, measurement of particle and beat luxes in the divertor region, and erosion studies. The DIII-D Advanced Divertor has been installed and bias and bafle experiments will begin in the fall of 1991 .

\section{INTRODUCTION}

Progress towards the gonl of therrnonuclear ignition has often been coupled with an increased understanding of, and improved control of, plasma surface interactions ${ }^{-8}$ which will continue to be an important issue in the success of the next generaticn of tokamak devices such as CIT, ITER, or NET.

The DIII-D tokamak is a versatile device $(a=0.7 \mathrm{~m}$, $R=1.7 \mathrm{~m}, \mathrm{~B}_{\mathrm{T}}=2.1 \mathrm{~T}, P_{\text {sux }}(\mathrm{NB}+\mathrm{ICH}+\mathrm{ECH}) \leq$ $24 \mathrm{MW}$, and inside or outside limiter, and single- or double-aull divertor discharges) which has employed a variety of wall conditioning tecirriques. We will discuss the wall conditionin's techniques employed on DIII-D and the resulting improvements in plasma operations. Divertor issues such as erosion, beat fluxes, and particle Aluxes in DIII-D will be presented, and the DIII-D Advanced Divertor Project (ADP) will be discussed.

\section{WALL CONDITIONING TECHNIQUES IN DIII-D}

The wall conditioning goal in DIII-D is twofold: reduction of impurity influx during tokamak discharges and particle control of hydrogen (in this paper hydrogen is used to refer to both bydrogen and deuterinu). Reducing impurity influx can consist of removing impurity atoms such as oxygen and carbon as gases or covering high $Z$ plasma facing surfaces with a low $Z$ material, e.g. carbonization. Particle control involves limiting the fueling of the discharge from the plasma facing surfaces.

A summary of the wall conditioning techniques used in DIII-D, in the approximate chronological order in which they were applied, is shown in Table I. The first three conditioning methods are used primarily for impurity removal and were initially applied early in the lifetime of the machine. The last three techniques can be effective for both impurity reduction and particle control and were implemented after graphite coverage in DIII-D was increased from 7.5 to $31 \mathrm{~m}^{2}$. With increased graphite coverage, the wall can become the dominant particle fueling source unless it is properly conditioned. ${ }^{5}$

\section{WALL CONDITIONING FOR IMPURITY REDUCTION}

The primary goal of conditioning the tokamak after a long opening is to reduce volatile low $\mathrm{Z}$ impurities, water, hydrocarbons, oxygen, etc., to permit burnthrough and the desired current levels without disruption. In DIII-D baking to $\leq 450^{\circ} \mathrm{C}$ inner wall and $\leq 350^{\circ} \mathrm{C}$ outer wall is the first method of conditioning after a machine opening once the global leak rrite has been reduced to $\leq 10^{-4} \mathrm{~T}$-L/sec. After baking, Taylor pulsed discharge cleaning (TDC) in hydrogen begins while the vessel is being baked. After TDC and baking, tokamak discharges can commence but baking and TDC 
Table 1

Conditioning Techniques in DIII-D

\begin{tabular}{|c|c|c|c|c|}
\hline Technique & Main Benefit & When Applied & Typical Parameters & Improvements in Tokamak Discharges \\
\hline Baking & $\begin{array}{l}\text { Impurity removal, } \\
\text { desorb } \mathrm{H}_{2} \text { for } \\
\text { lower recycling }\end{array}$ & $\begin{array}{l}\text { After machine } \\
\text { opening isotope. } \\
\text { ehangeover, low } \\
\text { recycling }\end{array}$ & $\begin{array}{l}\text { To } \leq 450^{\circ} \mathrm{C} \text { insids } \\
\text { wall, } \leq 350^{\circ} \mathrm{C} \\
\text { outside wall }\end{array}$ & $\begin{array}{l}\text { Used primarily in conjunction } \\
\text { with other techniques. }\end{array}$ \\
\hline $\begin{array}{l}\text { Taylor type } \\
\text { pulsed discharge } \\
\text { cleaning (TDC) }\end{array}$ & $\begin{array}{l}\text { Oxygen and } \\
\text { hydrocarbon } \\
\text { removal }\end{array}$ & $\begin{array}{l}\text { After machine } \\
\text { opening }\end{array}$ & $\begin{array}{l}\mathrm{I}_{\mathrm{P}} \sim 10 \mathrm{kA} \\
\mathrm{V}_{\mathrm{LOOP}} 15 \mathrm{~V}, \\
\mathrm{P} \sim 0.1-0.2 \mathrm{mT} \text { (abs) } \\
\mathrm{H}_{2} \text { or } \mathrm{D}_{2}\end{array}$ & $\begin{array}{l}\text { Baseline conditioning technique } \\
\text { used extensively through } 1987 \\
\text { and after machine openings. }\end{array}$ \\
\hline $\begin{array}{l}\text { Hydrogen glow } \\
\text { discharge } \\
\text { cleaning }\end{array}$ & Impurity removal & $\begin{array}{l}\text { After a disruption } \\
\text { (followed by } \\
\text { HeGWC) or after } \\
\text { machine opening) }\end{array}$ & $\begin{array}{l}I \leq 8 A_{1} \\
V \sim 250-400 V\end{array}$ & $\begin{array}{l}\text { Enhances recovery after } \\
\text { disruptions. }\end{array}$ \\
\hline $\begin{array}{l}\text { Helium glow } \\
\text { wall conditioning } \\
\text { (HeGWC) }\end{array}$ & $\begin{array}{l}\text { Hydrogen } \\
\text { desorption } \\
\text { (lower recycling) } \\
\text { and impurity } \\
\text { removal }\end{array}$ & $\begin{array}{l}\text { Routinely applied } \\
\text { before every } \\
\text { tokamak discharge }\end{array}$ & $\begin{array}{l}T_{\text {wall }} \sim 20-40^{\circ} \mathrm{C} \\
V_{\text {asode }}=300-500 \mathrm{~V} \\
\text { lanode } \sim 1-7 \mathrm{~A}, \text { typ. } \\
\alpha\left(\leq 8 \mu \mathrm{A} / \mathrm{cm}^{2}\right) \\
P \sim 1-4 \mathrm{mTorr}\end{array}$ & $\begin{array}{l}\text { After routine application: } \\
\text { - Lower recycling and } \bar{n}_{e} \text { (ohmic) } \\
\text { - Observation of ohmic } H \text {-mode } \\
\text { - Observation of limiter } H \text {-mode } \\
\text { - Faster disruption recovery } \\
\text { - Reliable low } q \text { operation } \\
\text { (leading to higher achievable } \beta_{\mathrm{T}} \text { ) }\end{array}$ \\
\hline $\begin{array}{l}\text { Neon (Argon) } \\
\text { glow discharge } \\
\text { conditioning }\end{array}$ & $\begin{array}{l}\text { Attempt to } \\
\text { reduce recycling } \\
\text { and control } \bar{n}_{e} \\
\text { during Hnomode }\end{array}$ & $\begin{array}{l}\text { Low recyeling } \\
\text { experiments }\end{array}$ & & $\begin{array}{l}\text { Hydrogen recyeling is reduced } \\
\text { but radiated power from neon } \\
\text { (Argon) retained in the walls limits } \\
\text { its effectiveness. }\end{array}$ \\
\hline Carbunization & $\begin{array}{l}\text { Reduce metal } \\
\text { impurity irflux, } \\
\text { especially during } \\
\mathrm{H} \text {-mode discharges }\end{array}$ & $\begin{array}{l}\text { Before high } \\
\text { eurrent operation }\end{array}$ & $\begin{array}{l}30-80 \mathrm{~nm} \text { carbon } \\
\text { film applied to } \\
\text { all plasma facing } \\
\text { surfaces then } \\
\text { bake to } 350^{\circ} \mathrm{C}\end{array}$ & $\begin{array}{l}\text { Peaked density profiles observed } \\
\text { during H-mode. } 3 \mathrm{MA} \text { double-null } \\
\text { discharges obtained and highest } \\
\text { values of stored energy. }(3.5 \mathrm{MJ}) \text {. }\end{array}$ \\
\hline
\end{tabular}

are employed between sessions of tokamak discharges until reproducible discharges with low radiated power $\left(P_{\mathrm{rad}} / \mathrm{P}_{\text {in }} \leqslant 0.4\right)$ are routinely obtained without disruptions. Recently, bydroger glow discharge conditioning has been substituted for TDC during vent recovery periods. The anount of vessel conditioning varies depending upon the length of the machine opening and the work inside the vessel. For example a 6 weet vent (Dec. 1989 - Jan. 1990) required 40 hours óc baking, $\sim$ jo hours of hydrogers glow cleaning, and 36 tokamak discharges, before the first beam heated H-mode discharge was achieved.

Impurity removal is also important after a disrup. tion or when developing plasma configurations in which plasma wall interactions occur in a new area of the vessel. The application of helium glow conditioning (HeGWC) with $T_{\text {wall }} \sim 20-40^{\circ} \mathrm{C}$ before every tokamak discharge has proven effective in removing impurities under such conditions. The details of the glow system have been described elsewhere. ${ }^{3}$ Removal efficiency after a disruption can be further enhanced by a shor session of hydrogen glow cleaning (typically 3 minutes) followed by HeGWC (typically 3 to 4 minutes). The techniques described above are effective in reducing the influx of low $Z$ impurities, namely carbon and oxygen. However metal impurity influx was observed in DIII-D high current ( $I_{p} \geq 2 \mathrm{MA}$ ) discharges. During the $\mathrm{H}$-mode phase of such discharges, the fraction of radiated power approached unity and radiation collapse occurred leading to the loss of $\mathrm{H}$-mode confinernent.

Carbonization of the DIII-D vessel has proven effective in reducing the influx of metallic impurities and in reducing tise fraction of radiated power in high current $H$-mode discharges. Carbonization of the DIII-D vessel followed procedures similar to those used on TEXTOR. ${ }^{7,3}$ An amorphous carbor layer was deposited during a glow session with elevated wall temperatures, $T_{w} \sim 150^{\circ} \mathrm{C}$, using a methane/helium gas mixture and 
an average wall current of $8 \mu \mathrm{A} \mathrm{cm}^{-2}$. Baking of the vessel to $350^{\circ} \mathrm{C}$ following the carbonization and $\mathrm{He}$ glow wall conditioning between tokamak discharges gave low recycling walls, and no loss of the ability to control the density with cold gas fueling. Central metal accumulation during $2 \mathrm{MA} \mathrm{H}$-mode discharges was decreased by a factor of 30 compared to precarbonization discharges. After carbonization, high current (up to $3 \mathrm{MA}$ ) doublenull divertor discharges were routinely obtained and a toroidal beta of $5 \%$ at the maximum toroidal field, $2.1 \mathrm{~T}$, was achieved.

\section{WALL CONDITIONING FOR PARTICLE CONTROL}

After the installation of $31 \mathrm{~m}^{2}(40 \%)$ graphite coverage in DIII-D, particle fueling from the walls was large enough that $\mathrm{H}$-mode discharges could not be obtained. ${ }^{8}$ The graphite tiles (Union Carbide type UCAR 1792) now cover all plasma facing surfaces in DIII-D which is subject to high beat fluxes. These surfaces include the entire floor, ceiling, inner wall, and areas of potential neutral beam shinethrough. Helium glow discharges were initiated before each tokamak discharge to desorb hydrogen and reduce wall fueling. After implementing HeGWC, particle control was sufficiently improved to re-establish $\mathrm{H}$--mode discharges and limiter and ohmic $\mathrm{H}$-modes were obtained. Low $q$ disruptions were reduced and disruption recovery during post vent phases or high current conditioning was achieved more rapidly than without $\mathrm{HeGWC}{ }^{5}$

Although wall fueling was reduced with HeGWC there can still he a large uncontrolled rise in density during the $\mathrm{H}$-mode phase of the discharge as shown in Figure 1. This density rise can limit the maximum stored energy since the edge density and pressure gradients increase until edge localized modes (ELMs) appear. Edge pressure gradients can approach the stability limit for ballooning modes and this may be responsible for the onset of at least some types of ELMs in DiII-D. ${ }^{10} \mathrm{An}$ estimate of the effect of wall fueling during the $\mathrm{H}$-mode phase can be obtained by ohserving the initial rate of density rise after the $\mathrm{L}$ to $\mathrm{H}$ transition. As shown in Figure 1 , the rats of density rise from the $\mathrm{L}-\mathrm{H}$ transition until the first ELM can be fit with good approximation by an exponential function of the form:

$$
N_{e}=N_{e o}+\Delta N_{e}\left(1-e^{-t^{\prime} / \tau_{N}}\right)
$$
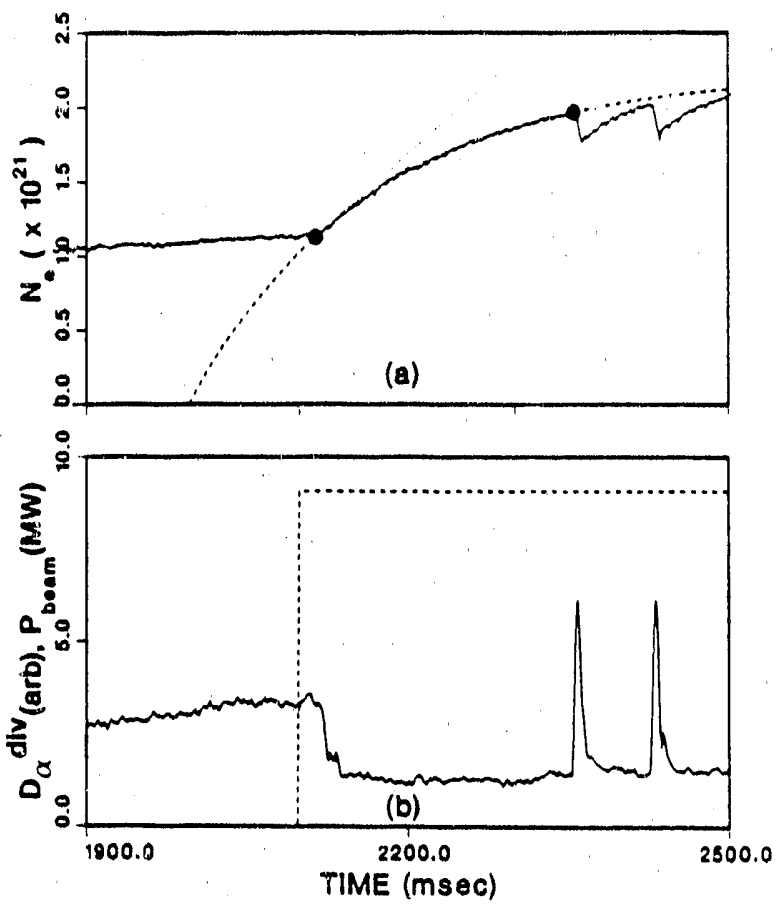

FIGURE 1.

(a) Total electron content in a diverted, 2.0 MA, 2.1 T, 6.8 MW $D^{\circ} \rightarrow D^{+}$, discharge inferred from 3 chords of an interferometer. The dashed curve shows the exponential fit to density rise. The initial slope of density increase at the L-H transition is indicated by the dotted line. (b) $D_{\alpha}$ emission from the divertor region showing the $\mathrm{H}$-mode transition and the first two ELMs (solid eurve) and neutral beam power (dashed curve).

where $N$ is the total number of plasma particles and $t^{\prime}=t-t_{L-H}$ and hence

$$
\frac{d N_{e}}{d t}\left(t^{\prime}=0\right)=\Delta N_{e} / \tau_{N} .
$$

From global particle balance,

$$
\frac{d N_{e}}{d t}-\Gamma_{\text {beam }}=-\frac{N_{e}}{\tau_{p}^{*}},
$$

where $r_{p}^{*}=\tau_{p} /(1-R)$ and $\Gamma_{\text {beam }}$ is the beam fueling in particles/sec. For simplicity we have assumed $Z_{\text {eff }}=1$ and no external gas fueling (which is the case during neutral beam injection). The value of $\tau_{N}$ inferred from this fit should not be interpreted as $\tau_{\mathrm{p}}^{*}$ since the recycling coefficient, $R(t)$ can change as a function of time ( $T_{e}$ and $T_{i}$ are monotonically increasing ove $i^{\prime}$ the time of the fit in Figure 1). From Eq. (3) the effectiveness of conditioning on the recycling coefficient can be evaluated by observing $\frac{d N_{s}}{d t}-\Gamma_{\text {beam }}$ at the $L$ to $H$ transition for discharges with similar parameters. A reduction in 
fueling has been achieved after carbonization and baking and is shown in Figure 2. There is a decrease of more than a factor of 2 in $\frac{d N_{e}}{d t}-\Gamma_{\text {beam }}$ after carbonization and $D_{\alpha}$ emission is reduced by a factor of $\sim 5$. These post carbonization discharges also exhibit a peaking in the density profile during $\mathrm{H}$-mode, plotted in Figure 3. Density peaking is an important issue in reactors such as CIT, ITER, and NET because fusion reactions occur primarily at the center of a discharge and the fusion yield is enhanced if a peaked density profile can be obtained without a degradation in the ion temperature. The effect of reduced wall fueling after carbonization and baking has lasted 40 discharges and then both wall fueling and H-mode density profiles return to their pre-carbonization characteristics.

\section{PLASMA-DIVERTOR INTERACTION}

Plasma surface interactions in the divertor region are an important issue for ITER and CIT where heat loads and particle Aluxes have the potential for significant erosion and impurity influx. ${ }^{11}$ DIII-D has successfully demonstrated divertor sweeping by moving the divertor strike points during the discharge. This has averaged the heat and particie fluxes over a much larger area and reduced the maximum heat flux by up to a factor of $3 .^{12}$ Studies have also been initiated on erosion and

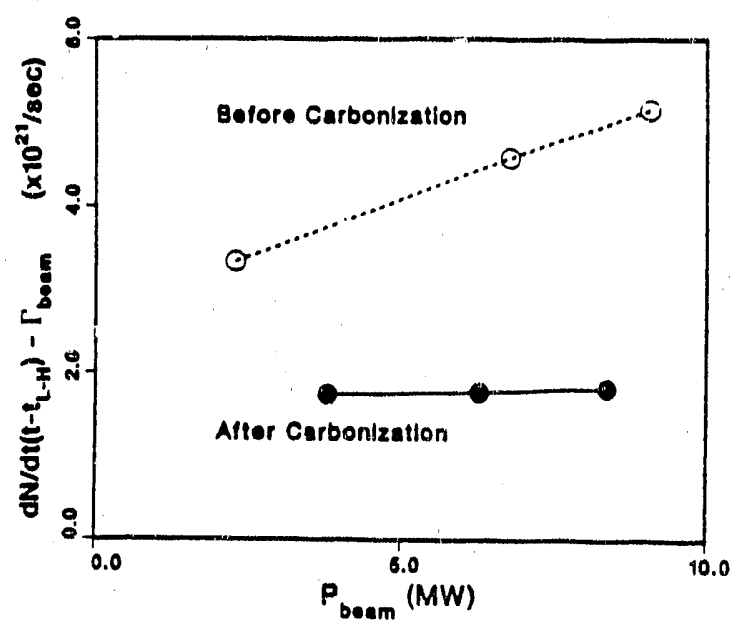

FIGURE 2.

Particle fueling at the $L$ to $H$ transition inferred from fits to the density rise [Figure 1 and $E_{q}$. (2)] before and after carbonization for discharges with similar shapes and target densities $\left(I_{p}=2 M A, B_{T}=2 T, N_{e}^{\text {tot }} \sim 1.2 \times 10^{21} \mathrm{~cm}^{-3}\right.$, and $\left.\mathrm{Z}_{\mathrm{x}}=-126 \mathrm{~cm}\right)$

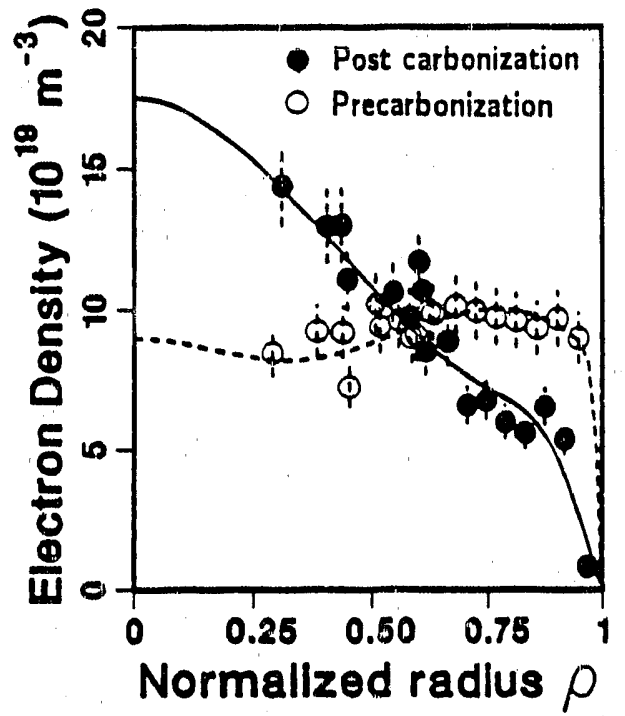

FIGURE 3.

Density profiles are more peaked immediately after carbonization and baking when compared to similar discharges with higher recycling (from Ref. 8 ). $\rho$ is the normalized plasma radius in flux space.

redeposition in the divertor region. From ex-situ profilometry measurements of graphite tiles after $\sim 2000$ discharges, the net erosion measured is significantly reduced when compared to code calculations without redeposition. ${ }^{19}$ Although the analysis is still in progress, it appears that redeposition in DIII-D is a large effect and must be included in calculating erosion rates. Heat and particle fluxes in the divertor region have been measured with an infrared and a camera viewing $\mathrm{H}_{\alpha}$ emission respectively. In general, for single null diverted discharges with the grad B drift toward the divertor, we find that particle fluxes are highest at the inner strike point and heat fluxes are highest at the outer strike point. ${ }^{14}$ This is also consistent with ex-situ external ion beam measurements of divertor tiles exposed to discharges in two successive campaigns (1000 and 3500 discharges respectively) which show the highest areal concentration of deuterium, 2-3.5 $\times 10^{18} \mathrm{~cm}^{2}$, in the region of the inner strike point. ${ }^{15}$

\section{THE DIII-D ADVANCED DIVERTOR PROJECT}

As discussed in Section 2, particle control during $\mathrm{H}$-mode is difficult to accomplish in DIII-D. An advanced divertor system shown in Figure 4 has been installed in DIII-D. The system consists of a toroidally 


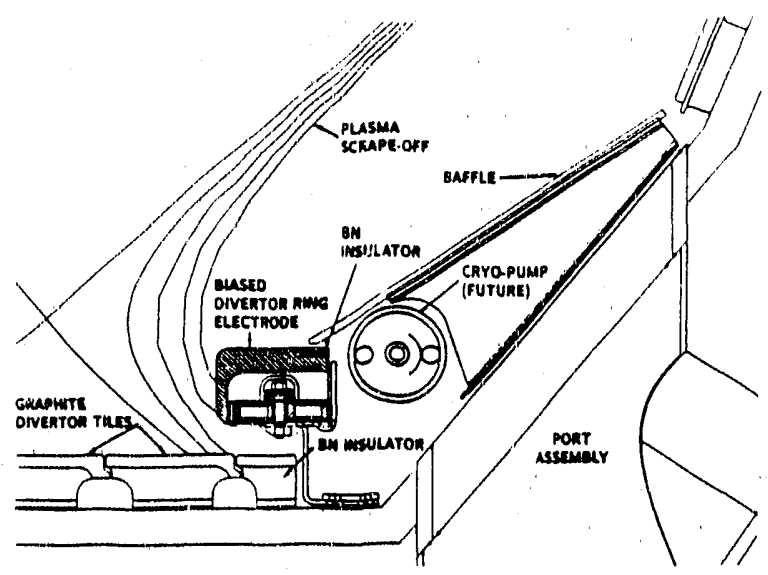

FIGURE 4.

Schematic of the divertor plate installed in the lower outside region in DIII-D and the future location of the cryo-pump. Flux lines from the diverted plasma scrape-off layer are also shown.

continuous, electrically biasable divertor plate electrode; a baffle that forms a closed outer divertor chamber; and (in 1991) a cyrogenic pump. The advanced divertor equipment is located near the lower outside radius of the machine so that ordinary DIII-D discharges can still be run without interaction with this new divertor. Then, for advanced divertor experiments, the versatile field shaping system in DIII-D positions the outer strike point of the divertor at either the aperture of this divertor or on the biased divertor plate itself, depending on the interaction desired. Biasing the divertor plate with respect to the rest of the vessel will drive current in the scrape-off region of the plasma. With these externally applied currents it may be possible is affect particle confinement times or reduce impurity influx. Helicity injection current drive experiments are also planned. Active pumping of particles, important for long-pulse machines, will be accomplished with the liquid helium cryo fump. The present DIII-D cryo design will give a $\mathrm{D}_{2}$ pumping rate of about $25 \mathrm{~T}-\mathrm{L} / \mathrm{sec}$ during a tokamak disciarge, which is equivalent to the particle flux from $14 \mathrm{MW}$ of neutral beam injection. The divertor bias plate is presently installed and experiments are scheduled to begin in the fall of 1990. The cryo pump is scheduled for installation in 1991 .

\section{CONCLUSIONS}

Methods of wall conditioning have evolved over the lifetime of DIII-D to include not only removal of low
$\mathrm{Z}$ impurities but also particle control of hydrogen and reduction of metal impurity influxes by carbonization. New methods of particle control are planned to further expand the parameter space in which DIII-D can operate. These include: boronization to realize longer term metallic impurity control and oxygen reduction, the biased divertor to affect particle fluxes and confinement, and the pumped divertor to aclively remove bydrogen during a discharge. Characterization of the divertor region is an important part of the DIII-D experimental plan and continuing studies are planned to measure particle fluxes, recycling, heat loading and erosion.

\section{ACKNOWLEDGMENT}

This work was supported by the U.S. Department of Energy under Contract No. DE-AC03-89ER51114.

\section{REFERENCES}

1. L. Oren and R.J. Taylor, Nucl. Fusion 17, (197'7) 1143.

2. G.M. McCracken and P.E. Stott, Nucl. Fusion 19, (1979) 889

3. J.D. Strachan, M. Bitter, A.T. Ramsey, et al., Phys. Rev. Lett. 58, (1987) 10n4.

4. P.C. Stangeby and G.M. McCracken, Nucl. Fusion 30, (1990) 1225.

5. G.L. Jackson, T.S. Taylor, and P.L. Taylor, General Atomics report GA-A19891 (1990), to be published in Nucl. Fusion.

6. N.H. Brooks, P. Petersen, and the DIII-D Group, J. Nucl. Mater. 145-147, (1987) 770.

7. J. Winter, J. Nucl. Mater. 161, (1989) 265.

8. G.L. Jackson, J. Winter, S. Lippminn, et al., General Atomics report GA-A2012s, to be published in J. Nucl. Mater.

9. G.L. Jackson, T.S. Taylor, S.L. Allen, et al., J. Nucl. Mater. 162-164, (1989) 489.

10. P. Gohil, M.A. Mahdavi, L. Lao, et. al, Phys. Rev. Lett. 61, (1988) 1603.

11. D.N. Hill, et al., in Proceedings of the Ninth International Conference on Plasma Surface Interactions, Bournemouth, United Kingdom, 1990.

12. D.N. Hill, General Atomics Report GA-A20187 submitted to Nucl. Fusion.

13. W.L. Hsu, Sandia National Laboratory, Livermore, private communication (1990).

14. S.L. Allen, M.E. Rensink, D.N. Hill, J. Nucl. Mater. 162-164, (1989) 80.

15. B.L. Doyle, Sandia National Labs Albuquerque, private communication (1989) 

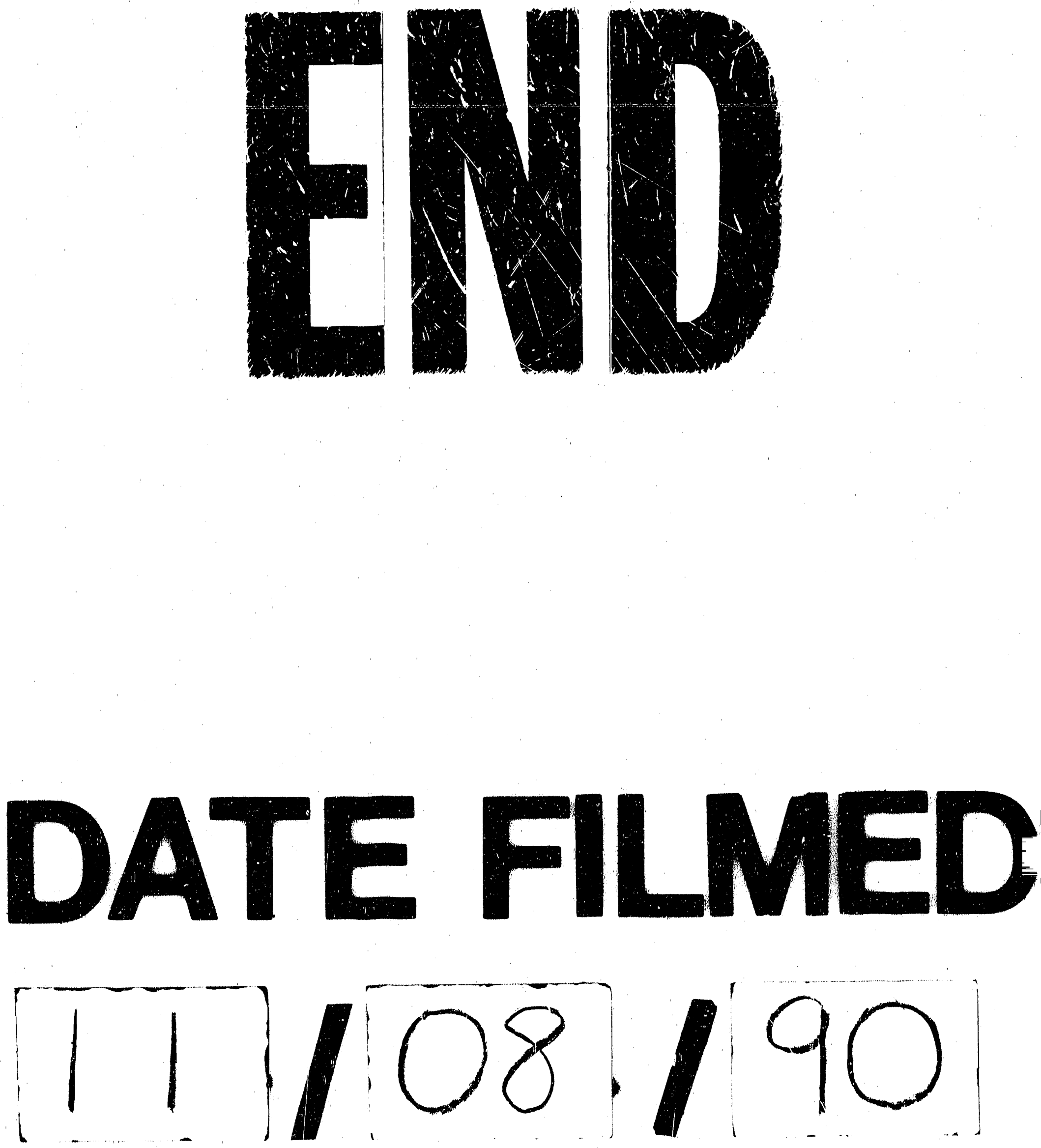
